\title{
The Nutritional Status of Pediatric Patients with Single Ventricle Undergoing a Bidirectional Glenn Procedure
}

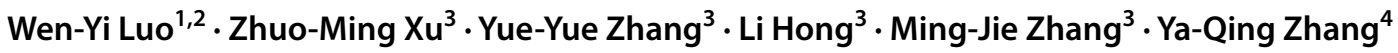

Received: 29 October 2019 / Accepted: 16 July 2020 / Published online: 22 July 2020

(c) Springer Science+Business Media, LLC, part of Springer Nature 2020

\begin{abstract}
Single ventricle (SV) physiology is associated with growth retardation in children. The nutritional status of pediatric patients with SV undergoing a bidirectional Glenn (BDG) procedure vitally affects the feasibility of the next operation stages. To explore the nutritional status and to identify specific anthropometric parameters relevant to short-term surgical outcomes in children with SV after the BDG procedure, this study included 151 patients who underwent the BDG procedure. Anthropometric assessments and Infant and Child Feeding Index (ICFI) scores were used to evaluate nutritional status. There was a significant statistical correlation between ICFI and malnutrition in both the height-for-age $Z$-score (HAZ) and weight-forage $Z$-score (WAZ) groups $(P<0.05)$. The clinical data, including ventilation time, nosocomial infection presence, pressure injury presence, peritoneal dialysis status, and total intensive care unit days, after BDG surgery were significantly different among the HAZ groups $(P<0.05)$, while nosocomial infection was different among the WAZ groups $(P<0.05)$. Children after BDG procedure had a high incidence of malnutrition, in addition to disease factors, the type and frequency of dietary intake were also important factors leading to worse clinical outcomes during hospitalization. Therefore, it is vital to maintain an optimal nutritional status in infants with SV who are undergoing a series of surgical procedures.
\end{abstract}

Keywords Nutrition $\cdot$ Single ventricle $\cdot$ Bidirectional Glenn procedure $\cdot$ Feeding index

Zhuo-Ming Xu

zmxcicu@163.com

Wen-Yi Luo

luowenyi@scmc.com.cn

Yue-Yue Zhang

zhangyueyue@scmc.com.cn

Li Hong

hongli@scmc.com.cn

Ming-Jie Zhang

zhangmingjie@scmc.com.cn

Ya-Qing Zhang

zhangyqf@163.com

1 Nursing Department, Shanghai Children's Medical Centre, 1678 Dongfang Rd, Pudong New District, Shanghai 200127, China

2 Shanghai Jiao Tong University School of Nursing, Shanghai 200025, China

3 Shanghai Children's Medical Centre, 1678 Dongfang Rd, Pudong New District, Shanghai 200127, China

4 Shanghai Jiao Tong University (Medical Science), 280 South Chongqing Road, Shanghai 200025, China

\section{Introduction}

Children with single ventricle (SV) physiology represent a heterogeneous group of patients with varying potential diagnoses. SV physiology is related to congestive heart failure and hypoxemia. Surgical interventions, including the bidirectional Glenn (BDG) procedure followed by the Fontan procedure, aim to optimize systemic and pulmonary circulation flow through staged palliation [1]. It is thought that early surgical intervention, and therefore the early elimination of volume overload and alleviation of cyanosis, leads to improved clinical outcomes and growth [2].

Previous studies have confirmed that SV is associated with growth retardation. Factors contributing to growth retardation in infants with SV include inadequate caloric intake, high metabolic demand, altered gastrointestinal pathology, and genetic and extracardiac abnormalities [3]. SV patients, who typically undergo a series of palliative surgical procedures, have difficulty achieving an adequate nutritional status and maintaining normal weight goals between surgical stages [4]. It has been shown that a lower weight-for-age $Z$-score (WAZ) is associated with interstage 
morbidity and is a modifiable risk factor for complications in the next operation stage [5].

The nutritional status of pediatric patients with SV undergoing the BDG procedure vitally affects the feasibility of the next stage operation. However, few studies have examined the relationship between nutritional status and surgical outcomes in children undergoing a series of palliative surgical procedures. Anderson et al. revealed that a low WAZ adversely affected the hospital length of stay after the BDG procedure in 100 infants with SV [6]. We believe that the patients with SV suffer from malnutrition and that their nutritional status, indicated by their WAZ, height-for-age $Z$-score (HAZ) and weight-for-height Z-score (WHZ), may potentially affect serious clinical outcomes after the BDG procedure.

The purpose of this study was to explore the relationship between diet and nutritional status and to identify specific anthropometric parameters relevant to short-term surgical outcomes in children with $\mathrm{SV}$ after the BDG procedure.

\section{Materials and Methods}

\section{Participants}

This study was a prospective case series including all patients who underwent the BDG procedure at Shanghai Children's Medical Center between August 2016 and December 2018. All subjects provided written informed consent to participate in this study. This project was approved by the Institutional Review Board (IRB) of the Shanghai Children's Medical Center, which is affiliated with the Shanghai Jiao Tong University's School of Medicine (SCMCIRB-2015003). Exclusion criteria included premature birth, chromosomal abnormalities, major congenital anomalies of the central nervous system, gastrointestinal disease, or transfer to another institution before discharge.

\section{Measurements}

\section{Anthropometric Assessment}

Heights and weights were recorded both at birth and on admission to the hospital by the nursing staff. Children were placed in a recumbent position, with their shoes removed and without any clothing, and height and weight were measured using an automated measuring instrument. The growth and nutritional status were evaluated using $z$-scores established by the World Health Organization (WHO) [7]. Weight-for-age (WAZ), height-for-age (HAZ), and weightfor-height (WHZ) were expressed as $z$-scores in standard deviation units. A $z$-score of less than -2 represented severe undernutrition [8], including stunting (HAZ $\leq-2)$, wasting $(\mathrm{WHZ} \leq-2)$ and underweight $(\mathrm{WAZ} \leq-2)$.

\section{Infant and Child Feeding Index}

The Chinese version of the Infant and Child Feeding Index (ICFI), based on the international ICFI [9], was created by the China Disease Prevention and Control Center's Nutrition Food Safety Office [10]. The total possible ICFI score is 23 According to the ICFI, the optimal feeding practices were defined for 3 different age groups: 6-8 months (breastfeeding plus gradual introduction of complementary foods), 9-11 months (same as 6-9, but increasing the amount and frequency of complementary feeding); and 12-36 months (continued breast-feeding for as long as possible, gradual transition to the family diet and a focus on dietary quality).

\section{Clinical Outcomes}

A structured questionnaire was administered to collect data on the clinical outcomes of the study participants. Demographic and clinical data, including gender, age, type of cardiac defect, and transcutaneous oxygen saturation level, were collected before surgery. Additional clinical data, including duration of cardiopulmonary bypass time, time of ventilation, presence of nosocomial infection, presence of pressure injury, peritoneal dialysis status, total intensive care unit days, and total hospital days, were also recorded after surgery.

\section{Statistical Analyses}

Continuous variables without a normal distribution were expressed as interquartile ranges. The Kruskal-Wallis and Chi-square tests were applied to compare the differences among the groups. The WAZs, WHZs and HAZs were analyzed with Kendall's tau-b test. All statistical analyses were performed using SPSS version 18.0. A value of $P<0.05$ indicated statistical significance.

\section{Results}

\section{Characteristics of Patients in the Three Groups}

The average age at the time of BDG surgery was $12.19 \pm 5.198$ month, the average weight was $8.34 \pm 1.618 \mathrm{~kg}$, and the average height was $72.10 \pm 6.521 \mathrm{~cm}$. Table 1 shows the characteristics of the patients in the three age groups. There were no significant differences in the basic demographic characteristics, except for neonatal surgery, among the groups. 
Table 1 Characteristics of patients in the three age groups

\begin{tabular}{|c|c|c|c|}
\hline $\begin{array}{l}6-8 \text { mo }(n=49) \text { frequency } \\
(\%) / \text { median (range) }\end{array}$ & $\begin{array}{l}9-11 \text { mo }(n=33) \text { frequency } \\
(\%) / \text { median (range) }\end{array}$ & $\begin{array}{l}12-24 \text { mo }(n=69) \text { frequency } \\
(\%) / \text { median (range) }\end{array}$ & $P$ value \\
\hline $27.0(55.1 \%)$ & $20.0(60.6 \%)$ & $45.0(65.2 \%)$ & $0.540^{\mathrm{b}}$ \\
\hline $22.0(44.9 \%)$ & $13.0(39.4 \%)$ & $24.0(24.8 \%)$ & \\
\hline $26.0(53.1 \%)$ & $20.0(60.6 \%)$ & $35.0(50.7 \%)$ & $0.754^{\mathrm{b}}$ \\
\hline $16.0(32.7 \%)$ & $10.0(30.3 \%)$ & $21.0(30.4 \%)$ & \\
\hline $7.0(14.3 \%)$ & $3.0(9.1 \%)$ & $13.0(18.8 \%)$ & \\
\hline $75.0(66.0-84.5)$ & $79.0(71.8-82.8)$ & $78.0(70.0-85.0)$ & $0.608^{\mathrm{a}}$ \\
\hline $38.0(77.6 \%)$ & $22.0(66.7 \%)$ & $61.0(88.4 \%)$ & $0.031^{\mathrm{b}}$ \\
\hline $11.0(33.3 \%)$ & $11.0(33.3 \%)$ & $8.0(11.6 \%)$ & \\
\hline $100.0(77.0-130.0)$ & $97.0(78.5-110.0)$ & $101.0(80.0-114.5)$ & $0.742^{\mathrm{a}}$ \\
\hline
\end{tabular}

Sex

Boy

Girl

Diagnosis

Dominant right ventricle

Dominant left ventricle

Others

$\mathrm{SpO}_{2}$ before BDG

Neonatal surgery

BT shunt

None

Duration of CPB

$100.0(77.0-130.0)$

$\mathrm{PH}$ pulmonary hypertension, $\mathrm{SpO}_{2}$ transcutaneous oxygen saturation, $B T$ shunt blalock taussig shunt, $C P B$ cardiopulmonary bypass

${ }^{\text {a }} P$ value calculated by the Kruskal-Wallis test

${ }^{\mathrm{b}} P$ value calculated by the Chi-square test

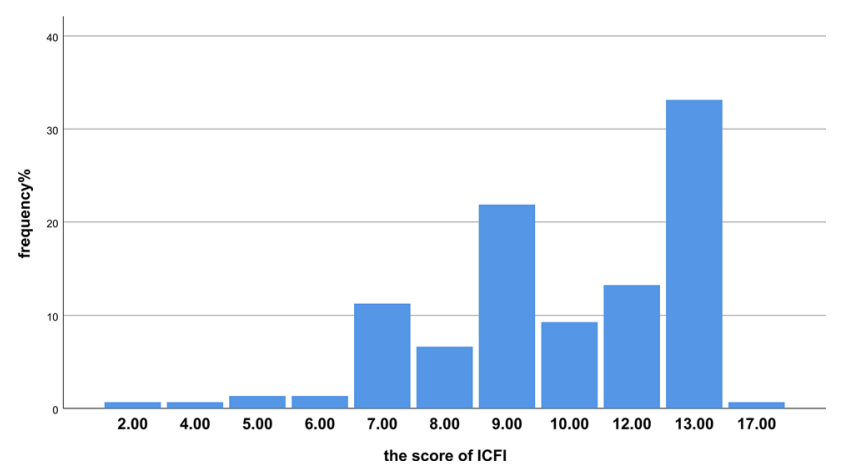

Fig. 1 Frequency distribution of ICFI scores in 6-24 months

\section{The ICFI Score in Different Groups and Distribution of Diet}

The median of ICFI scores of children at all ages was 10. Figures 1 and 2 demonstrate the distribution of ICFI in children of different ages, and Table 2 shows the food frequency in the 7 days before BDG surgery.

\section{ICFI and Nutritional Status}

The prevalence, distribution and types of malnutrition observed in the three groups are shown in Table 3 . There was a significant statistical correlation between ICFI and malnutrition in both the HAZs and WAZs $(P<0.05)$.

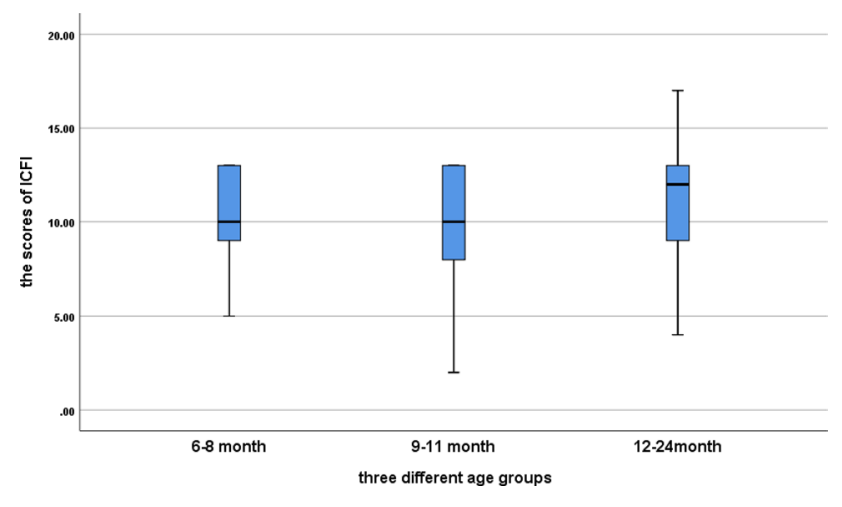

Fig. 2 Distribution of ICFI in children of different ages

\section{Nutritional Status and Clinical Outcomes}

The clinical data, including time of ventilation, presence of nosocomial infection, presence of pressure injury, peritoneal dialysis status, and total intensive care unit days, after BDG surgery were significantly different among the HAZ groups $(P<0.05)$, while nosocomial infection was different among the WAZ groups $(P<0.05)$.

\section{Discussion}

In this study, the mean WAZ, HAZ and WHZ of children with $\mathrm{SV}$ before the BDG procedure were lower than those recommended by the WHO [11]. It was obvious that the nutritional status of children with SV was lower than that of healthy infants. Early studies showed that the median WAZ 
Table 2 The ICFI scores and diet distributions in the three groups

\begin{tabular}{|c|c|c|c|c|c|}
\hline & & $\begin{array}{l}6-8 \text { mo }(\mathrm{n}=49) \text { median } \\
\text { (range)/frequency }(\%)\end{array}$ & $\begin{array}{l}\text { 9-11 mo }(\mathrm{n}=33) \text { median } \\
\text { (range)/frequency }(\%)\end{array}$ & $\begin{array}{l}12-24 \text { mo }(\mathrm{n}=69) \text { median } \\
\text { (range)/frequency }(\%)\end{array}$ & $P$ value \\
\hline ICFI & Total score & $9.0(8.0-10.0)$ & $12.0(9.0-12.0)$ & $13.0(9.0-13.0)$ & $<0.001$ \\
\hline \multirow[t]{2}{*}{ Vegetables } & 1 point & $5.0(10.2 \%)$ & $25.0(75.8 \%)$ & $20.0(29.0 \%)$ & \\
\hline & 2 points & 0.0 & 0.0 & $14.0(20.3 \%)$ & \\
\hline \multirow[t]{2}{*}{ Fruit } & 1 point & $11.0(22.4 \%)$ & $10.0(30.3 \%)$ & $27.0(39.1 \%)$ & \\
\hline & 2 points & 0.0 & 0.0 & $21.0(30.4 \%)$ & \\
\hline \multirow[t]{2}{*}{ Eggs } & 1 point & $8.0(16.3 \%)$ & $12.0(36.4 \%)$ & $29.0(42.0 \%)$ & \\
\hline & 2 points & $10.0(20.4 \%)$ & $19.0(57.6 \%)$ & $34.0(49.3 \%)$ & \\
\hline \multirow[t]{2}{*}{ Fish/poultry } & 1 point & $5.0(10.2 \%)$ & $30.0(90.9 \%)$ & $23.0(33.3 \%)$ & \\
\hline & 2 points & $5.0(10.2 \%)$ & $1.0(3.0 \%)$ & $28.0(40.6 \%)$ & \\
\hline \multirow[t]{2}{*}{ Bean products } & 1 point & $3.0(6.1 \%)$ & 0.0 & $10.0(14.5 \%)$ & \\
\hline & 2 points & 0.0 & $3.0(9.1 \%)$ & $13.0(18.8 \%)$ & \\
\hline \multirow[t]{2}{*}{ Milk products } & 1 point & $20.0(40.8 \%)$ & $18.0(54.4 \%)$ & $6.0(8.7 \%)$ & \\
\hline & 2 points & $2.0(4.1 \%)$ & $10.0(30.3 \%)$ & $44.0(63.8 \%)$ & \\
\hline Grains & 1 point & $12.0(24.5 \%)$ & $3.0(9.1 \%)$ & $11.0(15.9 \%)$ & \\
\hline
\end{tabular}

$P$ value calculated by the Kruskal-Wallis test

Table 3 ICFI and nutritional status of the three groups

\begin{tabular}{lccc}
\hline & $\begin{array}{l}6-8 \text { mo }(\mathrm{n}=49) \text { median } \\
\text { (range)/frequency }(\%)\end{array}$ & $\begin{array}{l}9-11 \text { mo }(\mathrm{n}=33) \text { median } \\
\text { (range)/frequency }(\%)\end{array}$ & $\begin{array}{c}\text { 12-24 mo (n=69) median } \\
\text { (range)/frequency }(\%)\end{array}$ \\
\hline HAZ & $-0.84(-1.96$ to 0.16$)$ & $-1.52(-2.61$ to -0.46$)$ & $-1.15(-2.53$ to -0.25$)$ \\
Stunting (HAZ $\leq-2)$ & $12.0(24.5 \%)$ & $13.0(39.3 \%)$ & $21.0(30.4 \%)$ \\
Correlation with ICFI & & & $0.256^{\mathrm{a}}$ \\
$\mathrm{r}$ & 0.455 & 0.797 & 0.777 \\
$P$ value & $0.001^{\mathrm{c}}$ & $0.000^{\mathrm{c}}$ & $0.000^{\mathrm{c}}$ \\
WHZ & $-0.31(-0.10$ to 0.16$)$ & $-1.03(-1.47$ to 0.33$)$ & $-0.84(-1.95$ to 0.05$)$ \\
Wasting (WHZ $\leq-2)$ & $3.0(6.1 \%)$ & $5.0(15.2 \%)$ & $17.0(24.6 \%)$ \\
Correlation with ICFI & & & 0.326 \\
r & 0.167 & 0.047 & $0.006^{\mathrm{c}}$ \\
$P$ value & $0.250^{\mathrm{c}}$ & $0.796^{\mathrm{c}}$ & $-1.22(-2.51$ to 0.27$)$ \\
WAZ & $-0.88(-1.77$ to 0.41$)$ & $-1.34(-2.05$ to 0.36$)$ & $24.0(34.8 \%)$ \\
Underweight $($ WAZ $\leq-2)$ & $10.0(20.4 \%)$ & $12.0(36.4 \%)$ & $0.030^{\mathrm{a}}$ \\
Correlation with ICFI & & & 0.563 \\
r & 0.496 & 0.205 & $0.008^{\mathrm{c}}$ \\
$P$ value & $0.000^{\mathrm{c}}$ & $0.252^{\mathrm{c}}$ & $0.178^{\mathrm{a}}$ \\
\hline
\end{tabular}

${ }^{\text {a }} P$ value calculated by the Kruskal-Wallis test

${ }^{\mathrm{b}} P$ value calculated by the Chi-square test

${ }^{\mathrm{c}} P$ value calculated by Spearman's test

was -1.3 (range -3.9 to 0.6 ) in children before the BDG procedure, similar to our finding. Therefore, malnutrition in children with SV is an urgent international problem [6].

Table 3 shows that the WAZs, HAZs and WHZs of the oldest age group (12-24 months) were significantly lower than those of the other groups (6-8 months and 9-11 months). Recent studies have revealed that long-term hypoxia is one of the main causes of nutritional deficiency in patients with SV [12]. In addition, due to the increase in pulmonary blood flow and possible heart failure after the SV stage 1 procedure, children often present labored breathing and tachycardia, which causes additional energy expenditure leading to severe growth retardation and protein-energy malnutrition before the BDG procedure [4, 13]. Francois et al. [14]. Reported that the growth of children with SV reached the lowest point before the BDG procedure; however, growth 
Table 4 Different clinical outcomes for nutritional status among the $z$-score groups

\begin{tabular}{|c|c|c|c|c|c|c|}
\hline & Ventilation time & Total ICU days & Total hospital days & $\begin{array}{l}\text { Ventilation- } \\
\text { associated } \\
\text { pneumonia }\end{array}$ & Pressure injury & Peritoneal dialysis \\
\hline \multicolumn{7}{|l|}{ HAZ } \\
\hline Normal & $13.0(7.0-25.5)$ & $5.0(4.0-6.5)$ & $16.0(12.0-22.0)$ & $1.0(1.0 \%)$ & $4.0(3.8 \%)$ & $24.0(22.9 \%)$ \\
\hline Stunting $(\mathrm{HAZ} \leq-2)$ & $20.0(10.8-26.5)$ & $6.0(4.0-10.0)$ & $14.5(11.8-21.0)$ & $7.0(15.2 \%)$ & $9.0(19.6 \%)$ & $21.0(45.7 \%)$ \\
\hline$P$ value & $0.048^{\mathrm{a}}$ & $0.022^{\mathrm{a}}$ & $0.540^{\mathrm{a}}$ & $0.001^{\mathrm{b}}$ & $0.002^{\mathrm{b}}$ & $0.005^{\mathrm{b}}$ \\
\hline \multicolumn{7}{|l|}{ WHZ } \\
\hline Normal & $14.0(7.8-28.0)$ & $5.0(4.0-7.0)$ & $15.5(12.0-21.3)$ & $5.0(4.0 \%)$ & $12.0(9.5 \%)$ & $36.0(28.6 \%)$ \\
\hline Wasting $($ WHZ $\leq-2)$ & $20.0(8.5-24.0)$ & $6.0(4.0-7.5)$ & $17.0(11.5-21.0)$ & $3.0(12.0 \%)$ & $1.0(4.0 \%)$ & $9.0(36.0 \%)$ \\
\hline$P$ value & $0.783^{\mathrm{a}}$ & $0.492^{\mathrm{a}}$ & $0.769^{\mathrm{a}}$ & $0.142^{\mathrm{b}}$ & $0.328^{\mathrm{b}}$ & $0.458^{\mathrm{b}}$ \\
\hline \multicolumn{7}{|l|}{ WAZ } \\
\hline Normal & $13.0(7.0-26.5)$ & $5.0(4.0-7.0)$ & $16.0(12.0-21.5)$ & $2.0(1.9 \%)$ & $6.0(5.7 \%)$ & $27.0(25.7 \%)$ \\
\hline Underweight (WAZ $\leq-2)$ & $21.0(10.8-24.0)$ & $6.0(4.0-8.3)$ & $15.0(11.8-21.0)$ & $6.0(13.0 \%)$ & $7.0(15.2 \%)$ & $18.0(39.1 \%)$ \\
\hline$P$ value & $0.111^{\mathrm{a}}$ & $0.045^{\mathrm{a}}$ & $0.829^{\mathrm{a}}$ & $0.008^{\mathrm{b}}$ & $0.066^{\mathrm{b}}$ & $0.097^{\mathrm{b}}$ \\
\hline
\end{tabular}

${ }^{\text {a } P}$ value calculated by the Kruskal-Wallis test

${ }^{\mathrm{b}} P$ value calculated by the Chi-square test

depends on the procedure conducted in the previous stage. A Blalock Taussig (BT) shunt can increase pulmonary blood flow and improve hypoxemia while simultaneously increasing the cardiac volume load. Although a pulmonary artery band can control congestive heart failure and protect the pulmonary vascular bed in patients, the pulmonary blood flow of children decreases, and hypoxia is aggravated [15, 16]. Moreover, symptoms worsen with increasing age, and children often exhibit a poor nutritional status before the BDG procedure.

In addition to the above diseases and surgical factors, our study found that ICFI scores were highly positively correlated with growth, represented by HAZ and WAZ. The lower ICFI score, the lower $Z$-score of nutritional status, indicating that a lack in dietary diversity and frequency was problematic. According to the distribution of dietary intake, the supplementary diet of each group was too conservative, especially in the 6-8 month age group (Fig. 2). The WHO [17] recommends that supplementary feeding should start at 6 months and the type of supplementary feeding should gradually increase with increasing age. Early or late introduction of supplementary feeding is not conducive to the growth and development of infants. Owens also pointed out that breast-feeding or bottle-feeding alone could not achieve a proper energy density, which is not ideal for the growth and development of children with congenital heart disease [18]. Previously published data on dietary intake and congenital heart disease are limited. The dietary intake records of patients with malnutrition and congenital heart disease [19] showed that the intake of energy and protein of children with congenital heart disease generally met the recommended requirements, but the dietary intake of iron, zinc and calcium was below the recommended levels. In our study, although the types of complementary foods began to increase in the 6-9 and 12-24 month age groups, the frequency of dietary intake, especially beans and grains, was still insufficient. Beans and grains mainly provide a large amount of carbohydrates and proteins that are rich in trace elements. Because of the immature gastrointestinal tract, poor digestion and limited chewing ability, children with SV often have feeding difficulties, specific food preferences, exhibit fussiness and antifeeding behaviors. Hill et al. [20]. Indicated that the feeding difficulties in SV children were significantly greater than those in the control group $(83 \%$ and $44 \%$, respectively). Another study [21] showed that $50 \%$ of the children with SV had difficulty feeding, and the WAZ and HAZ of the SV group were lower than those of the control group $(-0.84$ vs. -0.33 and -1.46 vs. -0.56 , respectively, $P<0.05)$. As a result, inadequate and simplified diet resulted in high detection rates of acute and chronic malnutrition in SV children in this study.

Furthermore, our study found that preoperative malnutrition may have an impact on the BDG procedure outcome (Table 4). Long-term malnutrition can lead to reduced protein reserves; increased vascular permeability; edema of the skin, mucosa and intestinal wall; and severe pressure injuries and ascites [6]. An imbalanced and simplified diet can lead to low levels of micronutrients and impaired immune function [22] and decreased muscle mass and strength [23], as well as affect ventilator extubation and the total time of the ICU stay. Moreover, cardiopulmonary bypass technology can also stimulate a systemic inflammatory response [24]. Because of their immature lungs, infants of a young age with long-term malnutrition are prone to 
lung injury due to cardiopulmonary bypass, which leads to a higher incidence of ventilator-associated pneumonia and a longer ventilator duration [25].

Our study also had some limitations. First of all, in our study, we found that the ICFI score was generally low, and the introduction of complementary food in children with SV is closely related to the feeding knowledge, behavior and economic status of caregivers [26-28]. However, this study did not include the analysis of relevant factors of caregivers, which need future research to explore the effect of caregiver factors on the ICFI score of children with SV. Secondly, our research was relatively geographically-specific with a Chinese adaptation of nutritional index. Due to the differences of food culture in different countries, the generalization of research results was limited. Thirdly, there was a relatively high incidence of BT shunts as the first palliation and a surgical technique reflecting $\mathrm{CPB}$ for the $\mathrm{BDG}$ procedure depending on age. This might limit some of the translational potential of the research to other healthcare systems.

\section{Conclusion}

SV physiology is associated with growth retardation in children. The nutritional status of pediatric patients with SV undergoing a BDG procedure vitally affects the feasibility of the next operation stage. Our study found that these children had a high incidence of malnutrition, in addition to disease factors, the type and frequency of dietary intake were also important factors leading to worse clinical outcomes during hospitalization. Therefore, it is vital to maintain an optimal nutritional status in infants with SV who are undergoing a series of surgical procedures.

Funding This work was supported by scientific research project from Shanghai Municipal Health Commission (20194Y0479).

\section{Compliance with Ethical Standards}

Conflict of interest We declare that we do not have any commercial or associative interest that represents a conflict of interest in connection with the work submitted.

\section{References}

1. Kaulitz R, Hofbeck M (2005) Current treatment and prognosis in children with functionally univentricular hearts. Arch Dis Child 90(7):757-762. https://doi.org/10.1136/adc.2003.034090

2. Reddy VM, Mcelhinney DB, Sagrado T et al (1999) Results of 102 cases of complete repair of congenital heart defects in patients weighing 700 to 2500 grams. J Thorac Cardiovasc Surg 117(2):324-331. https://doi.org/10.1016/s0022-5223(99)70430-7
3. Slicker J, Hehir DA, Horsley M et al (2013) Nutrition algorithms for infants with hypoplastic left heart syndrome; birth through the first interstage period. Congenit Heart Dis 8(2):89102. https://doi.org/10.1111/j.1747-0803.2012.00705.x

4. Kelleher DK, Laussen P, Teixeira-Pinto A, Duggan C (2006) Growth and correlates of nutritional status among infants with hypoplastic left heart syndrome (HLHS) after stage 1 Norwood procedure. Nutrition 22(3):237-244. https://doi.org/10.1016/j. nut.2005.06.008

5. Slicker J, Sables-Baus S, Lambert LM et al (2016) Perioperative feeding approaches in single ventricle infants: a survey of 46 centers. Congenit Heart Dis 11(6):707-715. https://doi. org/10.1111/chd. 12390

6. Anderson JB, Beekman RH, Border WL et al (2009) Lower weight-for-age $\mathrm{z}$ score adversely affects hospital length of stay after the bidirectional Glenn procedure in 100 infants with a single ventricle. J Thorac Cardiovasc Surg 138(2):397-404.e1. https://doi.org/10.1016/j.jtcvs.2009.02.033

7. Dibley MJ, Staehling N, Nieburg P, Trowbridge FL (1987) Interpretation of z-score anthropometric indicators derived from the international growth reference. Am J Clin Nutr 46(5):749 762. https://doi.org/10.1016/S0271-5317(87)80094-5

8. De Onis M, Bloessner M (1997) Who global database on child growth and malnutrition. World Health Organization, Geneva

9. Ruel MT, Menon P (2002) Child feeding practices are associated with child nutritional status in Latin America: innovative uses of the demographic and health surveys. J Nutr 132(6):1180-1187. https://doi.org/10.2307/2656665

10. Ling Y, Guo Z, Yaowu S et al (2012) Methodology of infant and young child feeding index for children aged 6-24 months in China. J Hyg Res 41(2):209-214 [in Chinese]

11. WHO Multicentre Growth Reference Study Group (2006) WHO child growth standards based on length/height, weight and age. Acta Paediatr Supply 450:76-85. https://doi. org/10.1111/j.1651-2227.2006.tb02378.x

12. Leitch CA, Karn CA, Peppard RJ et al (1998) Increased energy expenditure in infants with cyanotic congenital heart disease. J Pediatr 133(6):755-760. https://doi.org/10.1016/s0022 $-3476(98) 70146-5$

13. Medoff-Cooper B, Ravishankar C (2013) Nutrition and growth in congenital heart disease: a challenge in children. Curr Opin Cardiol 28(2):122-129. https://doi.org/10.1097/hco.0b013 e32835dd005

14. Francois K, Bove T, Panzer J et al (2012) Univentricular heart and Fontan staging: analysis of factors impacting on body growth. Eur J Cardiothorac Surg 41(6):e139-e145. https://doi. org/10.1093/ejcts/ezs194

15. Esmaily-Moghadam M, Hsia TY, Marsden AL et al (2015) The assisted bidirectional Glenn: a novel surgical approach for firststage single-ventricle heart palliation. J Thorac Cardiovasc Surg 149(3):699-705. https://doi.org/10.1016/j.jtcvs.2014.10.035

16. Alsoufi B, Manlhiot C, Ehrlich A et al (2015) Results of palliation with an initial pulmonary artery band in patients with single ventricle associated with unrestricted pulmonary blood flow. J Thorac Cardiovasc Surg 149(1):213-220. https://doi. org/10.1016/j.jtcvs.2014.08.007

17. WHO, Unicef, USAID, et al (2008) Indicators for assessing infant and young child feeding practices: part I definitions. World Health Organization, Geneva

18. Owens JL, Musa N (2009) Nutrition support after neonatal cardiac surgery. Nutr Clin Pract 24(2):242-249. https://doi. org/10.1177/0884533609332086

19. Hansen SR, Dorup I (2010) Energy and nutrient intakes in congenital heart disease. Acta Paediatr 82(2):166-172. https://doi. org/10.1111/j.1651-2227.1993.tb12632.x 
20. Hill G, Silverman A, Noel R et al (2014) Feeding dysfunction in single ventricle patients with feeding disorder. Congenit Heart Dis 9(1):26-29. https://doi.org/10.1111/chd.12071

21. Hill GD, Silverman AH, Noel RJ et al (2014) Feeding dysfunction in children with single ventricle following staged palliation. J Pediatr 164(2):243-246. https://doi.org/10.1016/j.jpeds .2013.09.030

22. Corman LC (1985) Effects of specific nutrients on the immune response: selected clinical applications. Med Clin North Am 69(4):759-791. https://doi.org/10.1016/S0025-7125(16)31018-5

23. Pichard C, Kyle UG, Morabia A et al (2004) Nutritional assessment: lean body mass depletion at hospital admission is associated with an increased length of stay. Am J Clin Nutr 79(4):613-618. https://doi.org/10.1093/ajcn/79.4.613

24. Wernovsky G, Wypij D, Jonas RA et al (1995) Postoperative course and hemodynamic profile after the arterial switch operation in neonates and infants a comparison of low-flow cardiopulmonary bypass and circulatory arrest. Circulation 92(8):2226-2235. https://doi.org/10.1161/01.CIR.92.8.2226

25. Kloth RL, Baum VC (2002) Very early extubation in children after cardiac surgery. Crit Care Med 30(4):787-791. https://doi. org/10.1097/00003246-200204000-00011
26. Jianqiang L, Shian Y, Guansheng M et al (2005) Distribution of feeding index and association between feeding index and growth of infants and young child aged 6-24 months. J Hyg Res 34(5):107-109 [in Chinese]

27. Aiqin Z, Xinglian L, Haiqing X (2009) Correlating study between feeding index and growth on infants aged 6-12 month. Chin J Child Health Care 17(6):632-634 [in Chinese]

28. Miao H, Huiwen Z, Ying G et al (2016) Complementary feeding practices and associated factors among infants with congenital heart disease: a multi-center survey. J Nurs Sci 31(3):30-33 [in Chinese]

Publisher's Note Springer Nature remains neutral with regard to jurisdictional claims in published maps and institutional affiliations. 